\title{
Research on the Method of Terminal Logistics Distribution based on the Urban and Rural Integration
}

\author{
Yuan Cai, Jinhua Chen \\ Changzhou College of Information Technology, Changzhou, 213164, China
}

Keywords: Urban and rural integration, Terminal logistics distribution, Method, Research

\begin{abstract}
This paper uses the method of practical analysis and historical review, makes full use of the management theory of supply chain and urban planology, and analyzes the potential of terminal logistics distribution, at the same time, it explores the market of the distribution of consumer goods and the future development direction of the end distribution of producer goods and discusses the method of the end distribution of urban and rural integration, mainly including three aspects, that is, value flow, technology platform and node selection, which aims at better promoting the distribution efficiency and economic benefits of the terminal logistics distribution in urban and rural.
\end{abstract}

\section{Introduction}

Under the background of the current stage of Chinese economic and social development, there are already some main functional areas entering the post industrialization stage, and it is in the period of optimal development. In this process, the resources and space gradually reflect the characteristics of the integration, and to some extent, it accelerates the process of urban and rural integration. In order to make the development of urban and rural integration more coordinated, it is necessary to coordinate the consumption and production data, so it is necessary to improve the distribution level of terminal logistics. The terminal logistics mainly includes two parts: production and consumption, which play an important role in the process of exchange between city and countryside, and is also the key content of operations and management between city and countryside. In the process of supply chain management, distribution enterprises must study and analyze the potential capacity and operation of logistics distribution market based on the framework of urban and rural integration. This paper will analyze and discuss the terminal logistics distribution in the process of the integration of urban and rural areas, and then actively optimize the integration of urban and rural areas, and promote the sustainable development of urban and rural areas in China.

\section{Overview of terminal logistics market potential}

Analysis of terminal logistics market potential can be carried out from the two aspects: consumer areas and production areas. With the improvement of people's living standards, the demand for the terminal distribution of goods is also increasing, while the supply chain management in the production areas and the core competitiveness of their own also have a positive impact on the terminal distribution.

\section{Analysis of the Market of consumer goods distribution}

Under the background of social development and industrial upgrading, the the technical labor force has been changed from buyer's market to seller's market. In this case, the labor itself begins to attach importance to the full play of its capacity, so the distribution into the home market comes into being ${ }^{[1]}$.

\section{The development process of distribution to home}

Distribution to home originates in the story of Wang Yongqing starting from selling rice, while the story is the most successful and typical case in the distribution of consumer goods to home among urban and rural residents. The economic development level of the urban and rural two yuan system is 
not high, because the traffic is relatively weak, and extremely lacks goods, so the phenomenon of "The Peddles" is more frequent. In the process of continuous exploration of economic system, the urban and rural market is gradually open, but at this stage, because the legal system is not perfect, resulting that the concept of direct marketing and pyramid selling are conflated, and then pyramid selling has a certain negative impact on the development of distribution to home.

In the process of the development of the distribution to home, the delivery network of urban and rural postal is established. The operation of China Post has a certain role in the construction of the distribution system. Especially, after the introduction of the relevant policies, the relevant policies begins to be promoted orderly, and the quality inspection and Quarantine Bureau has also carried out the corresponding engineering, to a certain extent, provides favorable conditions and environment for the development of the distribution into people's homes ${ }^{[2]}$.

After the development of the "Twelfth five Year Plan", the secondary distribution system of the society has been improved, and the development process of urban and rural integration has been effectively promoted. The scale and quantity of the large scale cities are increasing, and it has enriched the connotation of the distribution to home and expanded it. Especially in the aspect of consumer goods, the flexible production of manufacturing industry has been strengthened, and the service consciousness of the logistics distribution personnel has been improved. Meanwhile, the application of electronic commerce has been expanded.People begin to understand and realize the importance of the distribution, and then make the activities and practice of the distribution into the new stage of development.

\section{Analysis of the driving force of the buyers in the distribution to home}

The driving force is the internal force generated by the organism, which belongs to the internal stimulus. Organisms can produce different needs, and if they do not meet the needs of the organism, the organism will produce a certain internal drive, and then cause the corresponding reaction which will meet its needs. In the distribution to home, the driving force is not only from the seller, but also in the buyer's needs.

The key to produce the driving force of buyers is to improve the living standards, in the process of reform and opening up, the economic construction as the center of development, and the actual effect is very obvious. The overall living quality of urban and rural residents has been improved, and the living standards have also been improved significantly. The development trend of integration of urban and rural areas and suburbanization, results that the family with a high living standards begins to move to the suburbs, so the purchase of the material basis of the family is gradually replaced by the third logistics enterprises and logistics department .

In addition, the increasing power of buyers' driving force is the faster work rythm . Because of the impact of the international metropolis, the number of large and medium-sized cities in China is increasing. The city scale expands unceasingly, which strengthens the time concept of office workers to a certain extent. In dealing with the relationship between family, work and life, the value of time is more and more reflected, so this also improves the urgent needs of the city residents for the distribution to a certain extent ${ }^{[3]}$.

Among them, the social division thinning has also increased the internal drive of the buyers. In the process of resources changing, the promotion of urban industries, and industrial upgrading will make the division of labor more detailed, so it also makes the practice of distribution to home more professional.

\section{Analysis of the market orientation of distribution to home}

From the development process of the developed countries, we can see that the economic development and social progress will certainly improve the needs of the individual, so the practice activity of distribution to home comes into being. In 2011, the annual average person' s net of rural residents in China has reached 6194 yuan, while the disposable income of urban residents reached 21810 yuan, so the proportion of consumption expenditure of rural residents in household food accounted for more than $40 \%$ of aggregate consumption expenditure, the proportion of the town is 
nearly $40 \%$. The above findings can indicate that the actual consumption capacity of urban and rural residents has entered a new period. As the income of urban and rural residents is quickly increasing, and the total retail sales of social consumer goods is also increasing rapidly, to a certain extent, it promote the development of practical activities of the distribution to home, and also gradually become the important material conditions of the specialization of distribution to household .

\section{Analysis on the development trend of terminal distribution of producer goods}

In the process of urban-rural integrated planning and industrial agglomeration in our country, the production management consciousness is raised to a certain extent. Especially under the situation of the continuous development of supply chain management concept, and terminal logistics of producer goods gradually manifests the feature of their integration, instant and the minimum transaction cost.

\section{The inspiration of commissioning operations concept of terminal distribution of producer} goods by the supply chain management idea

In the Competitive Advantage, the attention is given to the theory content of value chain, and in Lean Thinking, not only expounds the idea of lean management, but also combines the practical cases of various countries, the value stream as the main clue, and then leads to the sales chain and supply chain ${ }^{[4]}$.

In the process of the gradual internationalization of the market economy, some large enterprises have begun to explore the relevant management ideas, and in the process of practice, they have accepted more attention and concern. In the nineties, the new progress in the study of supply chain theory came into being. And the relevant academic papers also summarizes the relevant theoretical experience, and supply chain management is to send the product or service to the enterprise network of end users worked in, and then realize the link of raw material supply to the final product delivery, to a certain extent, the management theory connotation of supply chain is rich.

Supply chain management is an integrated approach that combines management method with the end customer satisfaction, but also makes the professional of terminal distribution of producer goods to be enhanced. From the micro perspective, we can use the planning and control of recreated the business process and manufacturing resources, to effectively achieve collaborative operations, and timely delivery, to ensure that the transaction costs are minimized. From the meso perspective, we can make full use of Internet/EDI as a support, and then achieve the purpose of sharing and technical support of the industry internal information, and ultimately to achieve the optimal allocation of resources at the macro level and the development of the principal-agent.

\section{The consolidation effect of core competence on the operation mode of the terminal distribution of producer goods}

In the new period, the market has been refined, so that the core competitiveness of enterprises has been recognized by most people. The theory of the core competitiveness makes the enterprise gradually achieve the operation mode of the terminal distribution that is confined to the professional logistics enterprises in the collocation and commission of material resources . The achievement of distribution outsourcing in terminal logistics, greatly reduced the cost of enterprise operation , especially in the actual operation process, the enterprise really get rid of the restriction. Therefore, the enterprise is no longer restricted by the operation ability and mode, and then gives full play to the important role of the value chain.

\section{Research on the operation path of terminal distribution}

If you want to convert the needs of terminal distribution market to a commodity trading, it must be supported by the technical platform. The technology platform of distribution to home needs to ensure that the logistics distribution center can collect the information of the urban and rural residents and the production data, and it can make a quick response, and make full use of the flexible production 
and processing system to ensure that the purchasing and distribution system meets the actual needs of users.

\section{The value process of terminal distribution}

The value process of terminal distribution includes two parts: one is the process of information , that is, starting from the market department receiving the customers' orders or from the market department predicting customers' demands, to a whole process of specific procurement and production plans; the second is the physical flow, that is, after the supplier starts to supply finished goods, finished goods, from the receiving, quality supervision, inspection and outbound of all aspects, to the process of sorting, packaging and quality inspection, the use of delivery to customers in the hands of all the process.

\section{Technology platform of terminal distribution}

Technology platform of terminal distribution on the basis of sensing, sound, light, electricity and mobile computer can realize automatic distribution operations, and through the automation and intelligent control in the distribution network, the logistics, capital flow and the flow of commerce cooperation are achieved effectively.

At present, the distribution system of the logistics terminal needs to guarantee of automatic sorting, and the online billing system needs to be supported by the electronic commerce, the transmission system, local network system as well as the bar code and RFID system all need to have the necessary technical links, to achieve efficient information flow and capital flow and logistics operation between the daily consumer goods and the production data distribution center, the terminal customer and the suppliers $^{[5]}$.

\section{Node selection of terminal distribution}

Whether the supply chain node selection is correct or not is directly related to whether or not terminal distribution can be realized. Because the work of terminal distribution is a systematic project, so the important factor to determine the efficiency of the system is the allocation of resources in the distribution center and supply chain node number, organization structure and service categories, etc..

The node selection of single type and direct -selling distribution

If the business scope of the distribution enterprise is the direct distribution mode of the single category, the structure of the organization is flat and has a linear feature. The direct selling enterprise usually belongs to the enterprise of the distribution product, but also can be a professional logistics enterprise which has the background of the distribution.

The node selection of multi-class and delegation distribution

At this stage, the process of the enterprise internationalization is constantly deepened, and the diversification of enterprise products is gradually emerging. Therefore, it is necessary for the enterprises and distribution enterprises to gradually form the characteristics of the distribution .

\section{Conclusions}

But above all, in the rapid development process of urban and rural integration, to speed up the pace of economic and social transformation, while in the upgrading process of transformation, the logistics industry should be given full play to the role, and the important of the third profit source of the logistics industry should be recognized. The logistics activities mentioned above have the following three functions: first, the function of foreign trade international logistics; second, the production of logistics operation that modern industrial cities rely on, that is the so-called the function of distribution,supply and transmission for the producer goods terminal logistics ; third, the function of terminal logistics distribution service for the consumer goods that the urban residents living needs. And the last two function are the key content of the research in the terminal logistics distribution. In the construction process of the integration of urban and rural areas, terminal logistics market plays an important role, and has great development potential. However, in order to improve the efficiency of 
distribution, we must carry out a detailed understanding of the operation path of the distribution, and then realize the full promotion of efficiency and benefit. Based on the analysis of the background of urban and rural integration, this paper analyzes the method of terminal logistics distribution under the background of the integration of urban and rural areas, and discusses the potential and future development trend of the terminal logistics market. The main purpose is to improve the efficiency and economic benefits of terminal logistics distribution, and continuously promote terminal logistics distribution in the process of the integration of urban and rural areas.

\section{Acknowledgments}

This paper was a project of natural foundation of Zhejiang province in 2014 , Which name is Research on Game Analysis of Logistics Park Management Model (LY14G020003); Scientific research foundation project, Which name is Research on the Path of Innovation and Development of Terminal Logistics, in Changzhou college of information technology

\section{References}

[1] Zhu Zhanfeng. Analysis on the route of the end distribution of the integration of urban and rural areas. Logistics Technology, 2012, 31(10):105-107,117

[2] Zhang Xin. Common distribution mode and decision path of terminal logistics -- Based on the analysis of the supply and demand of electricity suppliers logistics and community service. Research on financial and economic, 2013(3):123-129.

[3] Yan Jun. A comparative analysis based on the logistics distribution model in the city. Chinese e-commerce, 2014(1):33.

[4] Zhang Rong,Wang Zhenhao. Bilevel programming model and algorithm for the node layout of distribution terminal in City. Journal of Tongji University (Natural Science Edition), 2012, 40(7): 1035-1040.

[5] Zhang Chunmei. Analysis on the common distribution in the city on the basis of social service platform and terminal logistics distribution. Logistics Technology (Equipment Edition), 2013(9):43-46. 